\title{
Integration Of Three Dimensional Paradigm - writing Ability And Professional Quality Education Of practical Writing teaching Is shallow

\author{
Wang Yanli ${ }^{1, a}$ \\ ${ }^{1}$ Primary Educational Dept., Wuhan City Vocational College, Wuhan, Hubei, PRC Postal Code: \\ 430067 \\ awangyanli1967@126.com
}

Keywords : Three dimensional paradigm Writing ability The integration of professional Quality education

\begin{abstract}
Combining with the actual practical writing teaching in high vocational colleges, based on national khalid ents education ideas, integrate the language of the three big functions, construction of practical writing knowledge - line - just three dimensional space teaching paradigm, and explore the practical writing course integration training students' writing skills, core ability and professional quality of $3 \mathrm{~d}$ integration education reform practice of teaching.

Applied articles as exchange of social information, the solution actual problem, specific affairs, guide people public opinion tool, its role in today's society more and more important. Writing is the internal knowledge structure, ability, emotion and so on the comprehensive reflection of the quality, the level of practical writing not only is one of the measure of personal ability, also to a considerable extent reflects the management department or unit to deal with daily business work quality and efficiency. In talent market competition, business writing ability has become an important aspect to measure the quality of the talents of unit of choose and employ persons, modern industry just gave it a louder - the name of a better writing skills.

Now, with the continuous development of our country's economy, the deepening reform of quality education in higher vocational colleges, vocational life must apply for job, planning, survey, etc. Various kinds of practical writing in the workplace writing has become extremely important content in professional quality. In order to adapt to the current employment environment, most colleges and universities have opened business writing course. Attaches great importance to college students' professional writing ability, have no doubt, the current is the key to how to give full play to the education function of practical writing course, actively explore writing ability and the integration of humanities quality, professional quality, the effective ways to creatively develop mutual penetration, integration of space, so that the students in the process of professional writing ability to develop, can not only enhance the cultural atmosphere, and can promote the good morality, integrity, innovation, excellent professional quality, to better promote the all-round development of students.
\end{abstract}

Practical writing in higher vocational colleges belong to the category of college Chinese courses. The author in the issue of the three dimensional paradigm - characteristics of higher vocational college language discipline study of orientation and teaching mode in the proposed of $3 \mathrm{~d}$ object subject orientation of college Chinese knowledge view. In the teaching practice, the author's research reference to China's basic education curriculum, with powerful righteousness three-dimensional curriculum goals as framework to guide the writing teaching, explore the writing skills of students, professional quality, $3 \mathrm{~d}$ object in core competence as one of the effective teaching approaches, in order to promoting the comprehensive qualities of macmillan righteousness comprehensive development of higher vocational students to provide practical guidance for reference, has achieved certain results.

1 Define the practical writing course orientation of higher vocational characteristic, the three dimensional goal curriculum system architecture macmillan righteousness.

Higher vocational education is based on students complete high school learning task of higher 
professional technology education, its main task is to develop in the production of the first line of practical operation and management. Don't both in secondary vocational education, to cultivate higher technical talents service, don't again in ordinary higher education, highlight vocational and technical education content. Practical writing course, then, higher vocational characteristic, higher technology applied talents training target must be around to select content; Balancing the subsequent development of students, to facilitate for the aftermath of the vocational education course (course) to provide quality, knowledge and ability of "necessary and sufficient" support and the cohesion and communication with higher undergraduate education. To do this, must change the original single take knowledge as the main body of theoretical education and as the integration of comprehensive ability training as the main body of the practical education. Basic education in our country curriculum provides the guiding ideology for integrated education.

Curriculum explicitly put forward by the knowledge and skills, process and methods, emotional attitude values of $3 \mathrm{~d}$ object to replace the original teaching outline of knowledge, skills and attitude of target system, be sure course education objectives, content framework, and put forward the related teaching and evaluation of the construction of the basic requirements. According to the basic idea of new, higher vocational education teaching practice, the author in teaching practice, boldly put forward the knowledge the righteous three-dimensional model of college Chinese course orientation, the reference to the concept of new, and one to one correspondence, including three dimensions: knowledge - knowledge and skills, line, process and methods, righteousness, emotion and attitude.

Practical writing teaching is the important content of the language, both humanism and professional, to do righteousness course basis is provided for the three dimensional paradigm of education orientation. As shown in figure:

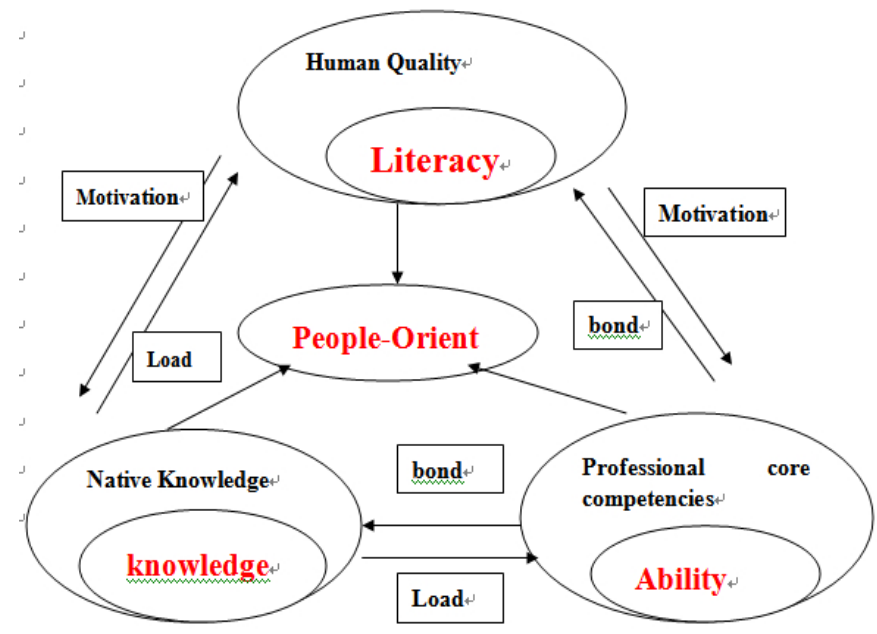

The positioning, has been clear about the application writing course combines teaching basic knowledge, training professional core ability, improve the quality of the humanities connotation of three big functions as one of the higher vocational characteristic discipline orientation. Course objective is to outline, for the eyes, clear scientific and feasible curriculum goals, course within the limited class hours to promote college students' writing knowledge, develop writing skills, set up humanistic ideas, master the thinking method, follow the humanistic spirit, macmillan righteousness integration development.

\section{The CDIO engineering education concept, reasonable and efficient use of school resources, "seek" to the student, for students to build knowledge the righteous three-dimensional integrated practice platform.}

What's the most difficult is practical writing teaching of practical writing teaching practice, from teachers to students, the lack of writing teaching is not the writing rules, not teaching paradigm, nor even writing training, but a lack of practice platform. Basic idea of practical writing is based on text, 
is born by business, - - used - is the consistency of curriculum teaching thought, is the practice of the practical writing platform. Real difficulty is that various affairs, solve practical style is unique for each transaction, alone, don't he, so how many kinds of practical style, so far no one textbook can give an answer. The teacher and students can feel the real situation of life affairs, in view of the transaction, write articles to solve issues. Various reasons limit our practical writing teaching can only be done in class, finish at school. No practice platform makes the practical writing writing teaching practicability into imaginary space of the literary writing.

In under the guidance of the concept, research best possible in view of the practical teaching, using the intercollegiate resources, establishment situation, so that the students in the process of simulation is "real" job writing training, the popular culture is to give students to find "what" to do. This "thing" is our school's annual college students winter games, college students business plan competition and practice.

Practical writing course to cultivate the students' professional writing ability, our objective is applicable, gm, enough. Apply is the student in the work in the professional use in the future, such as legal professional litigation class instrument to write with, normal professional teaching plan writing, etc.; Gm's students in daily life in the future used in all kinds of personal affairs, such as cover letter, CV, summary, etc.; Enough is applicable, general level. Annual school university student winter games, college students business plan competition both school-wide public activities, provides many specific transaction requires students to face the solution: in dealing with affairs, choose what kind of article in line with what kind of specification, which is easy to slip affect the solution of the transaction and so on, can provide training practice of general writing ability. Our school is in higher vocational colleges, all specialized attaches great importance to the combination of student education, the students from grade one start almost have at different times of the training and practice. Practice is a college student with their professional zero distance contact, in dealing with various kinds of professional affairs will face all sorts of things, such as preschool children education students inform parents to participate in activities to write a letter to parents', marketing professional students to write advertising copy, etc., can provide training for the practice of writing ability.

3 Reform the classroom teaching methods, to explore team by teams of students as the main body in the writing teaching, to work, judgment, selection, division of labor, writing - share mutual change - teaching, the teacher led - tip - review - development for the process of "OTPAE five-step training method".

OTPAE five-step training method is according to the concept of action-oriented teaching method, the classroom teaching Task project, according to the target (Object) - the Task (Task) - preparation (Prepare), Action (Action), assessment (Action) five steps of scientific training, OTPAE five-step training method, with ability to form the core for the teaching, ability training points in each section, according to the target (specific learning goals every festival) - Task (describe the ability to point in the actual work tasks in the state, displaying the significance of learning) - ready to (the ability to understand and grasp the point list and instructions should know content), Action (driven by Task, role playing, case study teaching methods, such as training) - assessment (by teachers, classmates and my self monitoring, timely understanding of learning outcomes, to get feedback) organization training.

Two years of educational practice convinced us that: based on the "khalid ents education" thought, with powerful righteousness three-dimensional target of curriculum structure, from the cultural characteristics of practical writing course and the perspective of professional quality development needs of higher vocational students, exert the integration function of practical writing class quality education, the implementation of the fusion of vocational humanistic quality education of a good try. Such teaching, training the students' ability of information; Cultivate the students' study and organization plan ability, cultivate the students' language competence and confidence; Cultivate the students' innovative ability and the team cooperation spirit; Did it make students to learn, happy, and to learn. 
Articles for vocational education in hubei subject to the three dimensional paradigm - higher vocational characteristic study of college Chinese subject orientation and teaching mode construction (G2014B022K)

\section{References}

[1] Peng Cui In practical writing writing as example shallow penetration in the professional quality and ability education in the teaching of BBS [J] vocational schools, 2012, (5)

[2] ai-ling wang curriculum reform important question: focus on the holistic development of human beings [J] education research, 2007, (9)

[3] Pan Chunyan humanistic quality in practical writing teaching and the integration of professional quality education research [J] career and education, 2010 (12)

[4] Shi Yangong high-skilled personnel training mode of cognition and practice [J] China's adult education, 2010 (12)

[5] jian-yong wang vocational ability under the perspective of language classes of planning and implementation [J] China's adult education, 2009 (9) 